\title{
ArtiFacts: Ivory Hemiarthroplasty: The Forgotten Concept Lives On
}

\author{
Bartek Szostakowski MD, Jakub Jagiello MBBS, FRCS (Tr \& Orth), \\ John A. Skinner MBBS, FRCS (Eng), FRCS (Orth)
}

\section{From the Column Editor,}

lthough Dr. San Baw developed and designed his own ivory hip arthroplasty prosthesis, he was not the first to use ivory for this procedure. Prof. Themistocles Glück used an ivory ball and socket joint to replace the femoral head of a patient in Germany in 1891-its earliest known use. In 1927, Dr. Ernest W. Hey Groves replaced the femoral head

A note from the Editor-in-Chief:

I am pleased to present to our readers the next installment of ArtiFacts. In this month's guest column, Bartek Szostakowski and his team from the Royal National Orthopaedic Hospital in the UK share the story of Dr. San Baw, a Burmese orthopaedic surgeon who developed and designed an ivory hip arthroplasty prosthesis. Szostakowski and his team also present radiographs of a then 93year-old Burmese patient whom they believe is one of the last individuals fitted with a functioning ivory hip replacement.

The authors certify that neither they, nor any members of their immediate families, have any commercial associations (such as consultancies, stock ownership, equity interest, patent/licensing arrangements, etc) that might pose a conflict of interest in connection with the submitted article. All ICMJE Conflict of Interest Forms for authors and Clinical Orthopaedics and Related Research ${ }^{\mathbb{R}}$ editors and board members are on file with the publication and in an ankylosed hip with a stemmed ivory head replacement-a design similar to contemporary hip resurfacing prostheses [1, 3, 7]. But unlike Prof. Glück and Dr. Hey Groves, Dr. San Baw and his team continued to use ivory materials throughout their careers. In fact, more than 500 handmade ivory hip replacements were successfully implanted in Burma between 1960 and 1995 by Dr. San Baw and his successors. Remarkably, Bartek Szostakowski and his team from the Royal National Orthopaedic

can be viewed on request.

The opinions expressed are those of the writers, and do not reflect the opinion or policy of $C O R R^{\circledR}$ or The Association of Bone and Joint Surgeons ${ }^{\circledR}$.

B. Szostakowski MD ( $₫)$,

J. Jagiello MBBS, FRCS (Tr \& Orth),

J. A. Skinner MBBS, FRCS (Eng), FRCS (Orth)

Joint Reconstruction and Sarcoma Unit, Royal National Orthopaedic Hospital NHS Trust, Brockley Hill, Stanmore, Middlesex HA7 4LP, UK

e-mail: bartek.szostakowski@gmail.com

J. Jagiello MBBS, FRCS (Tr \& Orth)

e-mail: jjagiello@doctors.net.uk

J. A. Skinner MBBS, FRCS (Eng), FRCS (Orth)

e-mail: john.skinner@ucl.ac.uk
Hospital in the UK believe they may have found the last remaining patient fitted with a functioning ivory hip replacement.

For a unique view of an otherwise standard procedure, take the time to read this month's ArtiFacts.

During his postgraduate training in orthopaedics at The University of Pennsylvania in the mid-1950s, Dr. San Baw considered using elephant ivory for hip replacements. Born in Tapon in the Tharawaddy District of Burma (now Myanmar), and trained in general and orthopaedic surgery at the Rangoon General Hospital in Burma, he presumed that ivory, apart from having better biologic properties compared to metal alloy, would also be cheaper and easier to obtain in Burma.

\section{Why Ivory?}

Ivory is durable, can easily be carved, and rarely splinters, making the material quite suitable for a hip prosthesis. The main component of ivory is dentine, an inorganic calcified tissue made from dentinal tubules embedded in a 


\section{ArtiFacts}

mineralized collagen matrix [2]. Ivory also contains cementum, a thin surface layer of bony material $[4,5]$. Functionally, the orientation of microlaminae and dentinal tubules may offer resistance to lateral stress from bending, in addition to resistance to axial compression [4].

In 1957, as Head of the Department of Orthopaedic Surgery at the General Hospital in Mandalay, a teaching hospital in the second-largest city in Burma, Dr. San Baw and his team began investigating the physical properties of ivory. Various mechanical tests indicated that ivory was weak in shear, strong in compression perpendicular to the grain, and most durable in compression parallel to the grains.

\section{Fine Craftsmanship}

Dr. Khin Maung Tu, a former assistant of Dr. San Baw, wrote in his 1972 dissertation that Dr. San Baw designed his novel ivory hip specifically for patients with longstanding nonunions of displaced femoral neck fractures, ankylosing spondylitis, and avascular necrosis. His designs were based on a Thomson hemiarthroplasty, but with major modifications to the stem, and later, to the head and neck junction. A craftsman who specialized in ivory carving shaped each hip replacement from the long axes of ivory tusks harvested from Burmese elephants that died naturally [7].

The first designs had solid, rounded, and serrated stems, but when they were exposed to static compression load tests in ex vivo conditions, the prostheses often fractured about 1 inch below the collar, and at an average load of 1848 pounds per square inch [7]. According to another assistant, Prof Kyaw Myint Naing, Dr. San Baw and his team designed a thicker and straighter design without serrations (Fig. 1), which improved the strength of the ivory prosthesis.

Each hemiarthroplasty was sterilized by immersion for 12 hours to 24 hours in Hibitane (Chlorhexidine) or Cetavlon (Cetrimide) and washed with sterile saline solution before implantation, according to Dr. Khin Maung Tu's dissertation.

\section{Government Funding}

In 1960, Dr. San Baw used his ivory prosthesis for the first time, replacing the ununited femoral neck fracture of an 83-year-old Burmese Buddhist nun [7]. According to Prof. Kyaw Myint Naing, Dr. San Baw generally used a Southern (posterior) approach to the hip, initially popularized by Austin T. Moore [8]. The femoral canal was prepared with the help of an arthroplasty set imported from the United Kingdom. Within 2 weeks of surgery, his first patient could mobilize without pain with the help of two crutches [7].

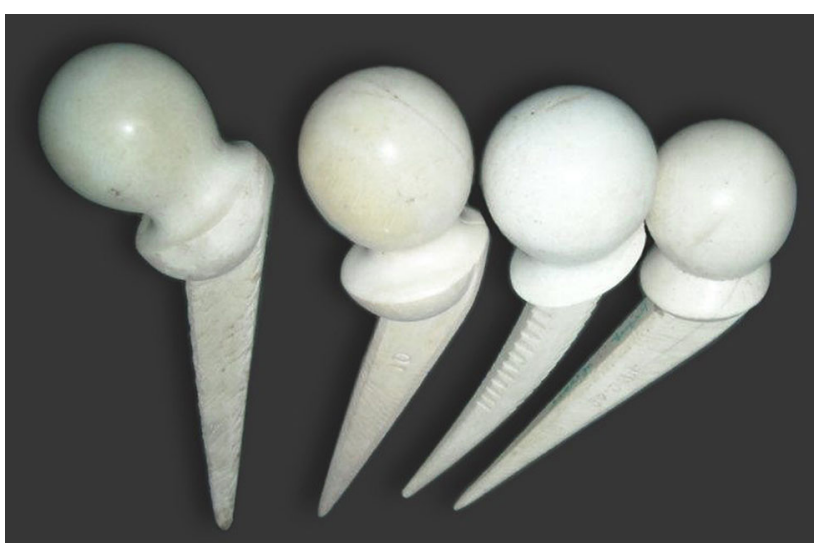

Fig. 1 Serrated designs of the ivory hip replacement and a nonserrated version with thicker stem and collar is shown (Published with permission from Bartek Szostakowski MD). 
For the next 5 years, Dr. San Baw used his own finances to fund his ivory hip project. But in 1965, with his resources dwindling, he sought the support of the Burmese government. Recognizing the procedure's successes, and in the interest of scientific research, the Burmese government decided to support the procedure financially, giving Dr. San Baw the necessary funding to fit more than 100 Burmese patients from ages 24 to 87 with an ivory replacement. From 1969 to the time of his retirement in 1980 , an additional 200 to 300 hip prostheses were implanted [7]. After recovery, most patients could perform everyday tasks like walking, squatting, and even playing sports.

According to Prof. Kyaw Myint Naing, Dr. San Baw experimented with ivory and manufactured other implants such as phalangeal prostheses, total elbow arthroplasties, cup arthroplasty, THAs, ivory plates, screws, Rush pins, and even a scaphoid prosthesis.

When he studied ivory stems from patients who died, Dr. San Baw found that the bone and ivory were fused together by a well-defined fibrous layer. In fact, in some areas, bone had incorporated into the ivory. According to his assistants at the time, the bonding could have been a sign of creeping substitution, a well-known process of bone remodeling most often seen during bone graft incorporation. This process is usually associated with nearcomplete resorption of graft materials, with simultaneous deposition of new, viable bone.

The nature of this particular biological bonding had not been previously described or confirmed. Careful examination of radiographs and CT scans suggests that the implant structure was not destroyed by resorption, even after many years from initial surgery $[6,7]$.

\section{The Last Patient with an Ivory Prosthesis?}

In our tribute to Dr. San Baw on the 30th anniversary of his death, we

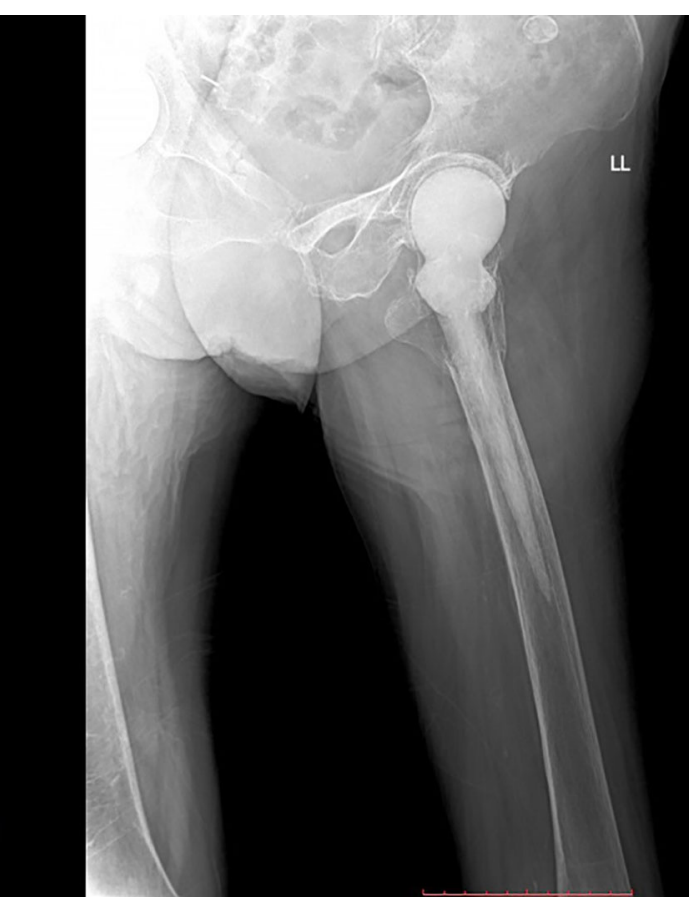

Fig. 2 A lateral view of the left hip shows the ivory hip replacement of a 93-year-old female patient at 20 years postimplantation. 


\section{ArtiFacts}

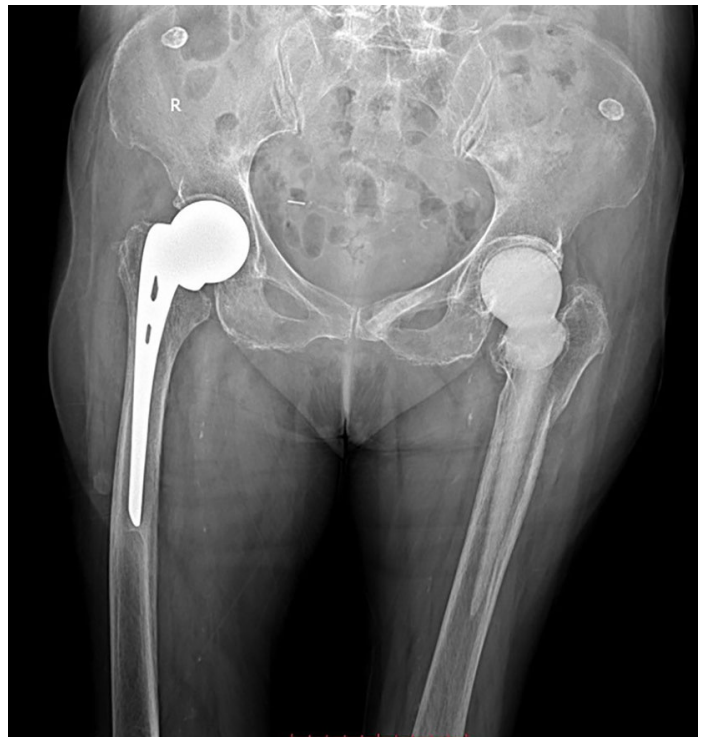

Fig. 3 An AP view of the 93-year-old patient shows an Austin Moore prosthesis implanted in the right hip. The left hip indicates an ivory hemiarthroplasty.

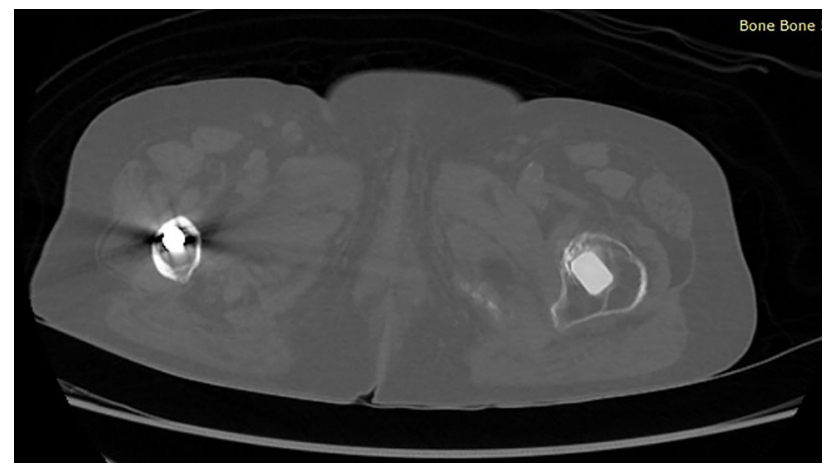

Fig. 4 Axial CT section showing the ivory hip stem on the left femur. Please note the high level of osseointegration between the ivory prosthesis and bone after 20 years. An Austin Moore hemiarthroplasty stem can be seen in the right femur. concluded: "We do not know how many Burmese with ivory prostheses are still alive. As of 1969, the youngest of Dr. San Baw's patients was aged 24 when the hip replacement was done and since Dr. San Baw undertook ivory hip replacements until about 1980, we estimate there could be up to a dozen or even more Burmese alive with ivory hip prostheses" [7].

Following the publication of our tribute, Dr. San Baw's son, found the individual whom we believe is the last remaining patient fitted with a functioning ivory hip replacement: A 93year-old woman from Burma. In 1994, the then-72-year-old patient fractured the neck of her left femur. Dr. Baw's former assistant, Prof. Meik, performed an ivory hemiarthroplasty (Fig. 2) at Mandalay General Hospital. In October 2014, the patient fractured her right hip and received an Austin Moore prosthesis at a local hospital in Burma (Fig. 3). According to the patient and her family, she had been using her ivory hip without limitation for those 20 years (Fig. 4).

Acknowledgments The authors would like to thank Prof. Kyaw Myint Naing and Prof. Meik for their expertise on the technical aspects of ivory hip replacement. We would also like to thank Prof. Myint Zan who helped obtain the necessary materials about his late father and ivory hip replacement. This article would not be possible without their help. 


\section{ArtiFacts}

\section{References}

1. Brand RA, Mont MA, Manring MM. Biographical sketch: Themistocles Gluck (1853-1942). Clin Orthop Relat Res. 2011;469:1525-1527.

2. Carda C, Peydro A. Ultrastructural patterns of human dentinal tubules, odontoblast processes and nerve fibres. Tissue Cell. 2006;38:141-150.

3. Groves, E. W. H. Some contributions to the reconstructive surgery of the hip. Br J Surg. 1927;14:486-517.
4. Locke M. Structure of ivory. J Morphol. 2008;269:423-450.

5. Owen R. Odontography; or a Treatise on the Comparative Anatomy of the Teeth; Their Physiological Relations, Mode of Development and Microscopic Structure in the Vertebrate Animals. London, UK; Hippolyte Bailliere: 1840-1845.

6. Roberts TT, Rosenbaum AJ. Bone grafts, bone substitutes and orthobiologics: The bridge between basic science and clinical advancements in fracture healing. Organogenesis. 2012;8:114-124.

7. Szostakowski B, Skinner JA. Dr San Baw: The man behind ivory hemiarthroplasty. Bone Joint J News. 2014;5:17-19.

8. Tronzo RG, ed. Surgery of the Hip Joint. $2^{\text {nd }}$ edition. New York, NY; Springer-Verlag; 1984. 